\title{
THE EFFECT OF HUMAN PLASMA ON THE ANTICOAGULANT ACTIVITY OF HEPARIN ${ }^{1}$
}

\author{
By C. LOCKARD CONLEY, ROBERT C. HARTMANN, AND \\ JOHN S. LALLEY \\ (From the Clinical Microscopy Division, Department of Medicine, The Johns Hopkins \\ University and Hospital, Baltimore)
}

\section{(Submitted for publication October 17, 1949; accepted, December 12, 1949)}

Soon after heparin became available for clinical use, the observation was made that there is a considerable variation in the response of human subjects to intravenously injected heparin. Crafoord (1) reported that patients after surgical operations required larger and more frequent doses of heparin than did normal individuals in order to retard coagulation to the same degree. This resistance to the action of heparin was thought to indicate an increased tendency to coagulation (2).

The effect of heparin on the coagulation time has been the subject of a number of clinical studies in which attempts have been made to demonstrate increased coagulability of the blood (3-11). Evaluation of these studies at present depends entirely upon statistical analysis of the concurrence of heparin resistance with clinically demonstrated tendency to thrombosis. Little fundamental knowledge exists concerning the variables which determine the results of "heparin tolerance" tests. While heparin effect is undoubtedly influenced to a certain extent by alterations in known blood clotting factors, it seems entirely possible that other conditions which are not concerned with coagulation may influence the anticoagulant activity of heparin in an important way.

When a certain amount of heparin is injected intravenously, the degree of prolongation of the clotting time of blood drawn following the injection would appear to be the resultant of a number of variables, some of which certainly have no relation to blood coagulation. The total volume of fluid in which the heparin is distributed, its rate of distribution, the rate of excretion and rate of inactivation all affect the concentration of heparin in the circulating blood following the injection.

1 This investigation was supported in part by a research grant from the Division of Research Grants and Fellowships of the National Institutes of Health, U. S. Public Health Service.
When heparin is added to blood in vitro, the situation is much more simple but the possibility remains that heparin may be inactivated or heparin activity affected by blood components not related to coagulation.

In view of the clinical interest in "heparin tolerance," it seems worthwhile to attempt to delineate the factors which influence the degree of response to heparin. The studies to be described were carried out in an effort to determine the extent to which heparin is inactivated by human plasma. In these experiments plasma samples from normal individuals and from patients with thrombotic and hemorrhagic disorders were heparinized following removal of the formed elements. The heparinized plasmas were incubated at $37^{\circ} \mathrm{C}$. for four hours. Their anticoagulant activity was then compared with that of 0.85 per cent sodium chloride solution containing the same concentration of heparin. The results provided no evidence that heparin was inactivated by any of the plasmas examined.

\section{METHODS}

Experiments were performed on fasting human subjects, including normal individuals and patients with certain diseases. Blood was drawn from an antecubital vein through a needle coated with silicone oil. ${ }^{2}$ After about $5 \mathrm{ml}$. of blood had been withdrawn, the syringe was disconnected from the needle and discarded. In this way any tissue juice which entered the needle during the venipuncture was rinsed out. A syringe treated both with silicone $^{8}$ and with silicone oil was then attached to the needle and $60 \mathrm{ml}$. of blood withdrawn. This blood was introduced into silicone-treated test tubes in an ice bath and immediately centrifuged in a refrigerated angle centrifuge (rim diameter $12.5 \mathrm{~cm}$.) for 10 minutes at 12,500 RPM. The temperature of the blood in the centrifuge cups was approximately $2^{\circ} \mathrm{C}$. Following centrifugation, the supernatant plasma was transferred to silicone-treated test tubes in an ice bath. Plasma prepared in this way

2 Silicone oil 9996-200 centistokes, General Electric Company.

3 Dri-Film 9987, General Electric Company. 
TABLE I

Effect on the anticoagulant activity of heparin of incubation with plasma from normal subjects and from patients with certain diseases

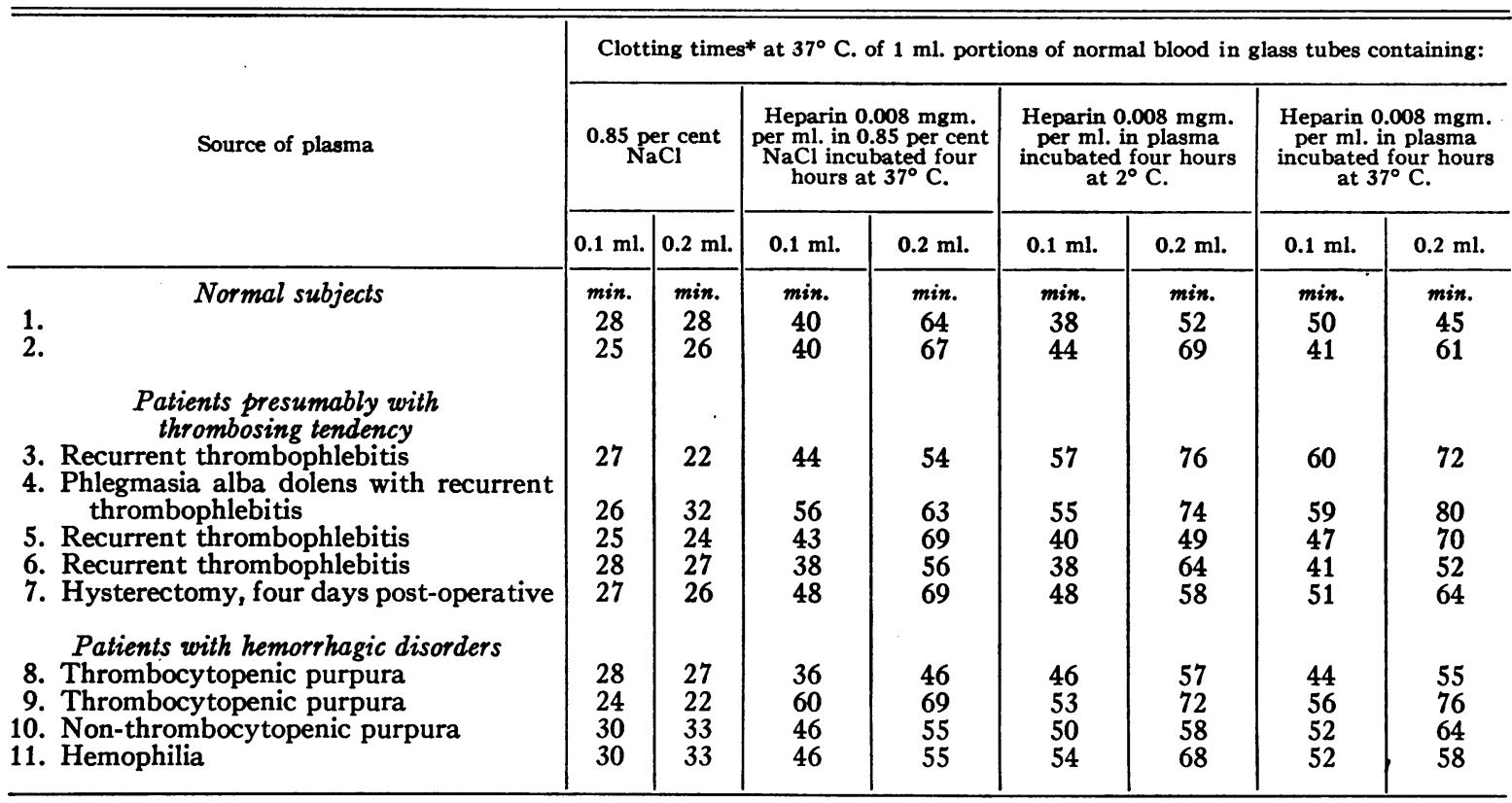

* In each instance clotting times were determined by a three-tube method. In order to simplify the table, the clotting time of blood in the third tube only is recorded.

was essentially free of formed elements and contained less than 50 platelets per $\mathrm{cmm}$. It could be kept in a fluid state indefinitely at $2^{\circ} \mathrm{C}$. in silicone-coated containers. The characteristics of native plasma obtained by this technique have been previously described (12).

Centrifuged plasma was heparinized by the addition of $0.6 \mathrm{ml}$. of 0.008 per cent heparin 4 in 0.85 per cent sodium chloride to $5.4 \mathrm{ml}$. of plasma, providing a final heparin concentration of $0.008 \mathrm{mgm}$. per $\mathrm{ml}$. Essentially platelet-free plasma containing this concentration of heparin was incoagulable in glass tubes at $37^{\circ} \mathrm{C}$. Portions of heparinized plasma were incubated in silicone-treated tubes for four hours at $2^{\circ} \mathrm{C}$. and at $37^{\circ} \mathrm{C}$., respectively. For controls, 0.85 per cent saline was heparinized to a concentration of $0.008 \mathrm{mgm}$. per $\mathrm{ml}$. and was also incubated at $2^{\circ} \mathrm{C}$. and at $37^{\circ} \mathrm{C}$. for four hours. A portion of the centrifuged plasma was kept without added heparin at $2^{\circ} \mathrm{C}$. during the four-hour incubation period and was similarly heparinized at the end of that time.

The heparinized plasmas and saline controls were then assayed for heparin activity by determining their anticoagulant effect on freshly drawn normal blood. In this assay, 0.1 and $0.2 \mathrm{ml}$. portions of the test substances were pipetted into $11 \times 100 \mathrm{~mm}$. Pyrex test tubes. One $\mathrm{ml}$. of fresh blood was quickly added to each tube, the tubes shaken to mix their contents, and the clotting times of the mixtures measured with a stopwatch. All clotting times were determined in triplicate at $37^{\circ} \mathrm{C}$.

4 Solution of Heparin, sodium salt, was obtained through the courtesy of Lederle Laboratories.
In three experiments plasma was acidified by the addition of hydrochloric acid. $\mathrm{N} / 3$ or N/6 hydrochloric acid in 0.85 per cent sodium chloride was employed, $0.3 \mathrm{ml}$. of the acid being added to $4.7 \mathrm{ml}$. of heparinized plasma. The $\mathrm{pH}$ of the plasma samples was determined using a Beckman Laboratory Model pH meter.

In experiments to determine the clot-promoting effect of crushed glass on heparinized plasma, normal plateletdeficient plasma was prepared as previously described and was heparinized by the addition of one part of heparin solution of appropriate concentration to nine parts of plasma. Crushed glass was made from Pyrex test tubes of the same lot used for clotting time determinations. Particles which passed through a 50 mesh screen but which were retained by a 100 mesh screen were employed. The crushed glass was washed in acid, rinsed with large volumes of distilled water, and dried in an electric oven. Specific amounts of crushed glass were added to plasmas containing varying amounts of heparin, and the clotting times were determined in triplicate at $37^{\circ} \mathrm{C}$. in Pyrex test tubes.

\section{RESULTS}

On incubation with plasma from normal human subjects, detectable inactivation of heparin did not occur. Similarly, plasma from patients with thrombotic and hemorrhagic disorders did not measurably alter the anticoagulant activity of heparin. The data presented in Table I show that 
there was no apparent difference in the anticoagulant action of heparin whether it was dissolved in plasma or in saline. The clot-retarding effect of heparin was the same when tested immediately following its addition to plasma as when tested after four hours of incubation with plasma at either $2^{\circ} \mathrm{C}$. or at $37^{\circ} \mathrm{C}$. In two experiments plasma was incubated with heparin in a concentration of 0.005 mgm. per $\mathrm{ml}$. With this lower concentration there was also no evidence of inactivation.

The "heparinase" obtained from rabbit liver was said to be optimally active at relatively low $\mathrm{pH}$ (5.3 to 6.8) (13). It seemed possible that human plasma might contain a similar enzyme which was inactive at the $\mathrm{pH}$ of the plasma in our experiments. Therefore, in three experiments plasma was acidified prior to incubation with heparin. The results of a typical experiment (Table II) indicate that no destruction of heparin took place in the $\mathrm{pH}$ range studied. Possibly blood may contain a heparin-inactivating enzyme which is active only at a lower $\mathrm{pH}$. If this is so, however, it seems unlikely that the enzyme could participate in the inactivation of heparin under physiologic conditions or under the conditions of the usual "heparin tolerance" test.

Previous studies have shown that the concentration of heparin required to inhibit coagulation is related to platelet concentration. When platelets are virtually absent, extremely low concentrations of heparin suffice to prevent coagulation (14). Experiments were carried out to determine whether, in the absence of platelets, the amount of glass surface in contact with plasma alters its heparin sensitivity. The data in Table III show

TABLE II

Effect on the anticoagulant activity of heparin of incubation with plasma at different $p H$ values

\begin{tabular}{|c|c|c|c|c|c|c|}
\hline \multirow{3}{*}{$\begin{array}{c}\text { pH of } \\
\text { plasma }\end{array}$} & \multicolumn{6}{|c|}{$\begin{array}{l}\text { Clotting time* at } 37^{\circ} \mathrm{C} \text {. of } 1 \mathrm{ml} \text {. portions of normal blood } \\
\text { in glass tubes containing: }\end{array}$} \\
\hline & \multicolumn{2}{|c|}{$\begin{array}{l}0.85 \text { per cent } \\
\mathrm{NaCl}\end{array}$} & \multicolumn{2}{|c|}{$\begin{array}{l}\text { Heparin } 0.008 \mathrm{mgm} \\
\text { per mi. in plasma } \\
\text { incubated for four } \\
\text { hours at } 2^{\circ} \mathrm{C} .\end{array}$} & \multicolumn{2}{|c|}{$\begin{array}{c}\text { Heparin } 0.008 \mathrm{mgm} \\
\text { per ml. in plasma } \\
\text { incubated for four } \\
\text { hours at } 37^{\circ} \mathrm{C} .\end{array}$} \\
\hline & $0.1 \mathrm{ml}$. & $0.2 \mathrm{ml}$. & $0.1 \mathrm{ml}$. & $0.2 \mathrm{ml}$ & $0.1 \mathrm{ml}$. & $0.2 \mathrm{ml}$. \\
\hline $\begin{array}{l}6.55 \\
7.3\end{array}$ & $\begin{array}{c}\min . \\
16 \\
16\end{array}$ & $\begin{array}{c}\min . \\
17 \\
17\end{array}$ & $\begin{array}{l}\min . \\
49 \\
51\end{array}$ & $\begin{array}{c}\min . \\
55 \\
61\end{array}$ & $\begin{array}{c}\min . \\
43 \\
44\end{array}$ & $\begin{array}{c}\min . \\
59 \\
56\end{array}$ \\
\hline
\end{tabular}

* The clotting time in the third tube only is recorded.
TABLE III

Effect of the addition of crushed glass on the clotting time of essentially platelet-free plasma containing varying concentrations of heparin

\begin{tabular}{|c|c|c|c|c|}
\hline \multirow{3}{*}{$\begin{array}{c}\text { Amount } \\
\text { of } \\
\text { crushed } \\
\text { glass }\end{array}$} & \multicolumn{4}{|c|}{$\begin{array}{l}\text { Clotting time at } 37^{\circ} \mathrm{C} \text {. of } 1 \mathrm{ml} \text {. portions of normal } \\
\text { platelet-deficient plasma* containing the concentration } \\
\text { of heparin and amount of crushed glass indicated }\end{array}$} \\
\hline & \multicolumn{4}{|c|}{ Heparin concentration } \\
\hline & $\mathbf{0}$ & $\begin{array}{c}0.00025 \\
\text { mgm. per ml. }\end{array}$ & $\begin{array}{l}0.00050 \\
\text { mgm. per ml. }\end{array}$ & $\begin{array}{c}0.00075 \\
\text { mgm. per ml. }\end{array}$ \\
\hline $\begin{array}{r}m g m . \\
0\end{array}$ & $\begin{array}{l}\min . \\
18 \\
18 \\
19\end{array}$ & $\begin{array}{l}\text { min. } \\
\text { no clots } \\
\text { in } \\
24 \text { hrs. }\end{array}$ & $\begin{array}{c}\text { min. } \\
\text { no clots } \\
\text { in } \\
24 \text { hrs. }\end{array}$ & $\begin{array}{c}\text { min. } \\
\text { no clots } \\
\text { in } \\
24 \mathrm{hrs} .\end{array}$ \\
\hline 75 & $\begin{array}{l}14 \\
14 \\
16\end{array}$ & $\begin{array}{l}50 \\
67 \\
93\end{array}$ & $\begin{array}{l}\text { partial clots } \\
\text { in } \\
24 \mathrm{hrs} .\end{array}$ & - \\
\hline 300 & $\begin{array}{l}7 \\
7 \\
7\end{array}$ & $\begin{array}{l}16 \\
19 \\
19\end{array}$ & $\begin{array}{l}48 \\
54 \\
63\end{array}$ & $\begin{array}{c}\text { partial clots } \\
\text { in } \\
24 \mathrm{hrs} .\end{array}$ \\
\hline 800 & $\begin{array}{l}6 \\
6 \\
6\end{array}$ & $\begin{array}{r}9 \\
9 \\
10\end{array}$ & $\begin{array}{l}21 \\
21 \\
24\end{array}$ & $\begin{array}{l}25 \\
31 \\
37\end{array}$ \\
\hline
\end{tabular}

* Platelets 40 per $\mathrm{cmm}$.

that with normal platelet-free plasma containing very low concentrations of heparin, the anticoagulant effect of the heparin was overcome by increasing the amount of glass surface in contact with the plasma. A plasma concentration of heparin of about $0.00025 \mathrm{mgm}$. per ml. was just sufficient to prevent coagulation of platelet-free plasma in a glass tube at $37^{\circ} \mathrm{C}$. With this concentration of heparin, the clotting time was very effectively shortened by the addition of crushed glass. With plasma heparin concentrations exceeding about $0.001 \mathrm{mgm}$. per ml., the addition of crushed glass did not cause coagulation to occur.

\section{DISCUSSION}

"Heparin tolerance" tests have been used empirically as a measure of blood coagulability. Few studies have been made to determine precisely what these tests measure. Jorpes (2) thought that heparin resistance might be the result of increased circulating thromboplastin. Waugh and Ruddick $(5,6)$ believed that the in vitro "heparin tolerance" test was essentially a titration of the amount of platelet and plasma thromboplastin in blood. Their experimental data indicated that heparin effect could be altered by adding thrombo- 
plastin to blood and also by changing the platelet concentration. De Takats $(3,4)$ suggested that variations in a number of plasma components as well as formed elements might influence heparin resistance. Quick (15) mentioned the possibility that variations in the amount of heparin co-factor in blood might alter the anticoagulant activity of heparin. Allen and his associates (16) have suggested that there may be "anti-heparins" in blood which influence its susceptibility to heparin. When coagulation defects exist so that thrombin formation is impaired, relatively small concentrations of heparin may have a marked anticoagulant effect. Platelet concentration is of the greatest importance in determining response to heparin, about 20 times more heparin being required to inhibit the coagulation of normal blood than is required for severely thrombocytopenic blood (14). Schmitz and Kühl (17) reported that the anticoagulant activity of heparin was greatly decreased after incubation with normal serum for 18 hours at room temperature. Jaques (13) isolated from rabbit liver an enzyme capable of inactivating heparin. The distribution of this "heparinase" is unknown. Possibly it is present in blood, and if present, variations in its concentration might alter the effect of added heparin.

In the studies reported here an effort was made to determine whether plasma contains substances which inactivate heparin. Under the conditions of these experiments, no evidence was obtained that normal plasma has any heparin inactivating power. Furthermore, plasma from patients with thrombotic disease had no demonstrable heparin neutralizing activity. Plasma from patients with certain hemorrhagic states did not augment the anticoagulant potency of heparin and appeared also to have no effect upon heparin action.

Heparin is not destroyed by thromboplastin (18) but the anticoagulant activity of heparin can be overcome by thromboplastin (19). It seems unlikely, however, that effective thromboplastin is present as such in the circulating blood since its presence should lead to prompt intravascular clotting. Plasma from the patients with thrombotic disease studied apparently did not contain measurable amounts of effective thromboplastin, since there was no detectable decrease in the anticoagulant effect of added heparin.
While platelets are very effective in overcoming the anticoagulant effect of heparin, platelets per $s e$ do not inactivate heparin. If platelets are removed from heparinized blood by centrifugation, the original anticoagulant activity of the heparin remains in the supernatant plasma. When the heparin concentration of blood is too low to prolong appreciably the whole blood clotting time, the presence of the anticoagulant can be readily demonstrated by reducing the platelet concentration by centrifugation (20). In essentially platelet-free plasma, a heparin concentration of the order of $0.00025 \mathrm{mgm}$. per $\mathrm{ml}$. is sufficient to inhibit coagulation in glass tubes at $37^{\circ} \mathrm{C}$.

Evidence has previously been presented that normal plasma in contact with a glass surface will clot in the absence of platelets (12). It seems probable that the initiation of coagulation of such plasma is the result of the conversion of a plasma thromboplastin precursor to an active thromboplastin. In the absence of platelets the clot-promoting effect of glass surfaces appears to be mediated by this conversion. In the experiments reported, it was shown that, within limits, the concentration of heparin required to inhibit coagulation of essentially platelet-free plasma was related to the area of glass surface to which the plasma was exposed. Presumably the amount of plasma thromboplastin "activated" was increased by contact with glass surface, and therefore the anticoagulant effect of heparin was correspondingly diminished.

While the experiments reported provide no evidence that plasma can inactivate heparin, the possibility cannot be excluded that in some abnormal states plasma might contain substances which would alter heparin activity. If this is the case, however, the appearance of such substances apparently is not a regular phenomenon in the type of cases in which alterations of "heparin tolerance" are said to occur.

\section{SUM MARY}

1. When normal human platelet-deficient plasma was incubated with heparin, there was no detectable alteration in the anticoagulant activity of the heparin.

2. Platelet-deficient plasma from patients with thrombotic and hemorrhagic disease had no demonstrable effect on the anticoagulant action of heparin. 
3. No evidence was obtained that a "heparinase" is present in human plasma.

4. In the virtual absence of platelets, the concentration of heparin required to inhibit coagulation was related to the glass surface area to which plasma was exposed.

\section{BIBLIOGRAPHY}

1. Crafoord, C., Preliminary report on post-operative treatment with heparin as a preventive of thrombosis. Acta chir. Scandinav., 1937, 79, 407.

2. Jorpes, J. E., Heparin: Its Chemistry, Physiology and Application in Medicine. Oxford University Press, New York, 1939.

3. de Takats, G., and Gilbert, N. C., The response to heparin; a test of the clotting mechanism. J.A. M.A., 1943, 121, 1246.

4. de Takats, G., Heparin tolerance. A test of the clotting mechanism. Surg., Gynec. \& Obst. 1943, 77, 31.

5. Waugh, T. R., and Ruddick, D. W., A test for increased coagulability of the blood. Canad. M. A. J., 1944, 50, 547.

6. Waugh, T. R., and Ruddick, D. W., Studies on increased coagulability of the blood. Canad. M. A. J., 1944, 51, 11.

7. Moses, C., The effect of digitalis, epinephrine, and surgery on the response to heparin. J. Lab. \& Clin. Med., 1945, 30, 603.

8. Ogura, J. H., Fetter, N. R., Blankenhorn, M. A., and Glueck, H. I., Changes in blood coagulation following coronary thrombosis measured by the heparin retarded clotting test (Waugh and Ruddick test). J. Clin. Invest., 1946, 25, 586.

9. Tuft, H. S., and Rosenfield, R. E., Detection of intravascular clotting tendency by heparin tolerance principle; methods and clinical application. Am. J. Clin. Path., 1947, 17, 862.
10. Hagedorn, A. B., and Barker, N. W., Response of persons with and without intravascular thrombosis to a heparin tolerance test. Am. Heart J., 1948, $35,603$.

11. Hagedorn, A. B., and Barker, N. W., Coagulation time of blood heparinized in vitro: correlation of results with those of the heparin tolerance test. J. Lab. \& Clin. Med., 1947, 32, 1087.

12. Conley, C. L., Hartmann, R. C., and Morse, W. I., II., The clotting behavior of human "platelet-free" plasma: evidence for the existence of a "plasma thromboplastin". J. Clin. Invest., 1949, 28, 340.

13. Jaques, L. B., Heparinase. J. Biol. Chem., 1940, 133, 445.

14. Conley, C. L., Hartmann, R. C., and Lalley, J. S., The relationship of heparin activity to platelet concentration. Proc. Soc. Exper. Biol. \& Med., 1948, 69, 284.

15. Quick, A., Discussion of paper by de Takats and Gilbert (3). J. A. M. A., 1943, 121, 1246.

16. Allen, J. G., Jacobson, L. O., and Grossman, B. J., A study of the plasma defect in patients whose bleeding is temporarily controlled by protamine sulfate or toluidine blue. J. Lab. \& Clin. Med., 1948, 33, 1480.

17. Schmitz, A., and Kühl, L., Fortgesetzte Untersuchungen über Heparin. Die Inaktivierung des Heparins im Blut. Ztschr. f. physiol. Chem., 1935, 234, 212.

18. Quick, A. J., On the action of heparin and its relation to thromboplastin. Am. J. Physiol., 1936, 115, 317.

19. Howell, W. H., and Holt, E., Two new factors in blood coagulation-heparin and pro-antithrombin. Am. J. Physiol., 1918, 47, 328.

20. Conley, C. L., Hartmann, R. C., and Morse, W. I., II., Circulating anticoagulants: a technique for their detection and clinical studies. Bull. Johns Hopkins Hosp., 1949, 84, 255. 